\title{
Cost Control of Mining Personnel Based on Wireless Communication Network from the Perspective of Operations Research
}

\author{
Hongyi Wang ${ }^{1}$ and Meichang Zhang $\mathbb{D}^{2}$ \\ ${ }^{1}$ Management Science and Engineering, Liaoning Technical University, Fuxin 123000, China \\ ${ }^{2}$ Mining Engineering, Liaoning Technical University, Fuxin 123000, China
}

Correspondence should be addressed to Meichang Zhang; zhangmeichang@lntu.edu.cn

Received 12 November 2021; Revised 7 December 2021; Accepted 13 December 2021; Published 10 January 2022

Academic Editor: Huihua Chen

Copyright (c) 2022 Hongyi Wang and Meichang Zhang. This is an open access article distributed under the Creative Commons Attribution License, which permits unrestricted use, distribution, and reproduction in any medium, provided the original work is properly cited.

\begin{abstract}
The sublevel caving method without sill pillar is used to improve the cost of mining. The analysis is performed according to unique geographical environment and the current mining technology of the mine. The wireless communication network is used to budget and control the work cost of mining. Simulation operation about unit explosive dosage, fan-shaped deep hole interval, hole bottom distance, and collapse step distance is performed. Experiments have shown that budget and control of the cost of mining workers with wireless communication technology can manage mining data and guide the design of mining data.
\end{abstract}

\section{Introduction}

The cost control by mining personnel is a relatively complex system. Due to the continuous changes in the production of mining factories, the cost control of mining personnel needs to consider the overall balance of different links, continuity, and uncertainty, in order to carry out effective identification and optimization, and control the cost of mining personnel of mine engineering. With the rapid development of science and technology, digitization and visualization technology have been widely used in various fields. As the main component of the mine, development plan for cost control of mining personnel is needed, digitizing and visualizing the mining activities, timely and accurately recording and expressing the engineering changes in the mine pit, and improving the mining level and work efficiency [1-3].

The construction of an integer model is used to optimize the location of fans in the network and the selection of structures in this paper. The cost of ventilation is normalized to minimize it. For the same problem, the nonlinear unmixed model covers special constraints and branch constraints, which are the basis for semiconstrained design, and optimizes the answer.

\section{Establishment of Operational Research Model}

The constrained flow network problem only includes the best deployment location of personnel and building selection to allocate personnel to all predetermined network branches [4-6]. The problem of nonholonomic constraints of the network will face a dual task. In addition to determining the best placement of personnel and the choice of structures, it is also necessary to control the people flowing into unclear branches.

2.1. Constrained Flow Network Problem. Because the distribution of personnel in the network is known, the constrained condition conditions do not need to be discussed, and then the objective function of this problem can be expressed by formula (3), and its constrained conditions are 


$$
\left\{\begin{array}{l}
\sum_{j=1}^{b}\left(R_{j}\left|Q_{j}\right| Q_{j}+H R_{j}-H N_{j}-H F_{j}\right)=0 \\
H R_{j}, H N_{j} \geq 0, j=1, \ldots, b
\end{array}\right.
$$

Obviously, this is a nonlinear programming model, which is transformed into a linear programming model by introducing bivariate $Y_{j}$ and the objective function is transformed by obtaining this value $Y_{j}$.

$$
\begin{aligned}
Y_{j} & =\left\{\begin{array}{ll}
1, & H F_{j}>0, \\
0, & \text { other, }
\end{array}, C_{p} Q_{j}=a_{j},\right. \\
\text { minimize } Z & =\sum_{j \in L} a_{j} H F_{j}+\sum_{j \in L} C_{j} Y_{j} .
\end{aligned}
$$

The constrained conditions are

$$
\left\{\begin{array}{l}
\sum_{j=1}^{b} b_{i j}\left(R_{j}\left|Q_{j}\right| Q_{j}+H R_{j}-H N_{j}-H F_{j}\right)=0 \\
H R_{j}, H F_{j} \leq 0, j=1, \ldots, b \\
H F_{j} \leq d_{j} Y_{j}, j \in L, \\
Y_{j}=(0,1) .
\end{array}\right.
$$

In the formula, $d_{j}=\max H F_{j}$. When $H F_{j} \neq 0, Y_{j}=1$; when $H F_{j}=0, Y_{j}=0$ 时. So when $Y_{j}=1, Y_{j}=0$, and a larger value may appear in $Z$.

2.2. Half Constrained Flow Network Problem. Assume that the minimum value $L_{j}$ and maximum values $U_{j}$ of branchers, respectively, flow to ambiguous branchers and are represented by the objective function [7].

$$
\operatorname{MinZ}=\sum_{j=1}^{L} C_{j} Q_{j} H F_{j}+\sum_{j=1}^{L} C_{j} .
$$

The constrained conditions are

$$
\left\{\begin{array}{l}
\sum_{j=1}^{b} a_{i j} Q_{j}=0 \\
\sum_{j=1}^{b} b_{i j}\left(R_{j}\left|Q_{j}\right| Q_{j}+H R_{j}-H N_{j}-H F_{j}\right)=0 \\
L_{j} \leq Q_{j} \leq U_{j} \\
H R_{j} \geq 0 \\
X_{j}=(0,1) \\
Q_{j} H F_{j} \geq P_{j}, X_{j}=1 \\
Q_{j} H F_{j}=P_{j}, X_{j}=0 \\
j=1, \ldots, b
\end{array}\right.
$$

where $P_{j}$ is the minimum power allowed on branch $j$.

It can be seen from the previously mentioned objective function and constrained conditions that they are all nonlinear. So we need to transform it into a linear programming. During the transformation, the decompression is first determined, and then, the solutions for each subset are established. All solutions need to form the elements that make up the aggregation $L$ for $X_{j}$. Finally, this nonlinear programming is a linear programming, and then, the best solution is selected. The specific method is verified in the following example.

\section{Specific Application of Operations Research}

Figure 1 is a cost network diagram of a miner. It is composed of nine branches and six nodes, and each wind resistance is constant. According to the specific situation, the personnel can be configured for seven minutes when branching. On 8 , the structures are at branches 3,5 , and 8 .

The distribution of personnel on each branch is shown in Table 1.

3.1. Problem Solving for Constrained Flow Network. We select the spanning tree $\{1,2,5,6,9\}$, and the matrix can be obtained $b_{i j}$

$$
b_{i j}=\left[\begin{array}{ccccccccc}
1 & 2 & 3 & 4 & 5 & 6 & 7 & 8 & 9 \\
-1 & 1 & 0 & 1 & 0 & -1 & 0 & 0 & 0 \\
0 & 1 & 0 & 0 & 1 & 0 & 1 & 0 & 0 \\
1 & 0 & 0 & 0 & 0 & 1 & 0 & 1 & 1
\end{array}\right] .
$$

Then, the objective function can be expressed as

$$
\begin{aligned}
\min Z= & C_{p} Q_{5} H F_{5}+C_{p} Q_{7} H F_{7}+C_{p} Q_{8} H F_{8} \\
& +C_{5} Y_{5}+C_{7} Y_{7}+C_{8} Y_{8} .
\end{aligned}
$$

The constrained conditions are

$$
\left\{\begin{array}{l}
-R_{1} Q_{1}^{2}+R_{2} Q_{2}^{2}+R_{4} Q_{4}^{2}-R_{6} Q_{6}^{2}=0 \\
R_{1} Q_{1}^{2}-R_{2} Q_{2}^{2}+R_{3} Q_{3}^{2}+H R_{3}-R_{5} Q_{5}^{2}-H R_{5}+H F_{5}=0 \\
R_{2} Q_{2}^{2}+R_{5} Q_{5}^{2}+H R_{5}-H F_{5}+R_{7} Q_{7}^{2}-H F_{7}=0 \\
R_{1} Q_{2}^{2}+R_{6} Q_{6}^{2}+R_{8} Q_{8}^{2}-H F_{8}=0 \\
H F_{5} \leq d_{5} F_{5} \\
H F_{7} \leq d_{5} F_{7} \\
H F_{8} \leq d_{5} F_{8}, \\
Y_{j}=(1,0), \quad j=5,7,8 \\
H R_{j} \geq 0, \quad j=3,5,8 \\
H R_{j} \geq 0, \quad j=5,7,8
\end{array}\right.
$$

After calculation, the best solution is to set up two personnel on branches 7 and 8 , respectively, where the wind pressure on branch 7 is $11330.6 \mathrm{~Pa}, 840.8 \mathrm{~Pa}$ of which is shared by branch 8 . The main auxiliary equipment is set on branch 3 .

The best solutions are usually difficult to be found for the multifunctional optimization problems. Most of them adjust each target in a balanced manner and meet the requirements based on the problem to obtain the best balanced solution 


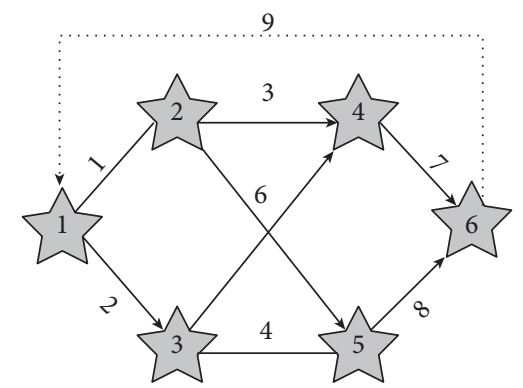

FIGURE 1: Cost network of mining personnel.

Table 1: Distribution of personnel in branches.

\begin{tabular}{lcccc}
\hline Branch & Wind resistance $R_{j}$ & Personnel $Q_{j}$ & Position of personnel & Structure placement \\
\hline 1 & 0.34 & 35.35 & & Allowable \\
2 & 0.41 & 37.02 & \\
3 & 0.54 & 18.02 & & Allowable \\
4 & 0.91 & 20.02 & Allowable & \\
5 & 1.43 & 17.02 & & Allowable \\
6 & 1.66 & 17.35 & Allowable & \\
7 & 0.22 & 35.02 & & \\
8 & 0.17 & 37.35 & 72.25 & \\
9
\end{tabular}

with certain accuracy and practical significance. Here, the decisive objective function and constraint conditions in the problem are shown. Fuzzy theory is combined with intelligent algorithms to solve chaotic optimization problems. The dark color of more than one thousand targets is most suitable for the best dextrin of the basic thousand single targets. In the fuzzy set of the optimal solution of each target, the solution of each target is satisfied as much as possible.

(1) The objective function of the formula MOP problem is complex and only provides a very large membership function. On the premise of satisfying the constraints as much as possible, the larger the objectives, the better, and there is an upper limit but no lower limit. The upper limit is the best value for each single goal optimization [8-10]. Therefore, the ray shape is selected as the correlation function for each target.

$\mu\left(f_{k}(X)\right)=\left\{\begin{array}{l}1, f_{k}(X)>c_{01}, \\ \frac{f_{k}(X)-c_{0 k}+\delta_{0 k}}{\delta_{0 k}}, c_{0 k}-\delta_{0 k}<f_{k}(X) \leq x_{0 k}, \\ 0, f_{k}(X) \leq c_{0 k}-\delta_{0 k} .\end{array}\right.$

In the formula, $\mu\left(f_{k}(X)\right)$ specifies the membership function $f_{k}(X)$ of the target. The target value $f_{k}(X)$ for the target optimization of the target monomer $c_{0 k}$. This is the added value of target $\delta_{0 k}$ accepted by policy makers, and it is determined by scaling to a certain extent on the basis of optimizing the target value into a single target (Figure 2).
The specific solution steps of the wireless communication network method are as follows:

Step 1. Use the following wireless communication network algorithm to find the optimal solution to the constraints of each single-objective function:

$$
\left\{\begin{array}{l}
\max f_{i}(X), i=1,2, \ldots, p \\
g_{i}(X) \leq 0, i=1,2, \ldots, m \\
h_{j}(X)=0, j=1,2, \ldots, l
\end{array}\right.
$$

Find the optimal solution of the constraint of the previously mentioned objective function.

Step 2. Stretch each single target value to a certain extent; that is, determine the added value

Step 3. The fuzzy of each objective function, that is, the function that determines the degree of membership of each objective function, is as follows:

$$
\mu\left(f_{k}(X)\right), k=1,2, \ldots, p \text {. }
$$

Define the satisfaction degree of all membership functions as

$\lambda=\min \left\{\mu\left(f_{i}(X)\right), \mu\left(f_{2}(X)\right), \ldots, \mu\left(f_{p}(X)\right)\right\}$.

Step 4. Substitute $c_{0 k} \delta_{0 k}$ into (3) to obtain expression of $p$ membership function.

Step 5. Based on the max-min law of the fuzzy set theory, the maximum satisfaction degree method is used to convert the multiobjective problem into a 


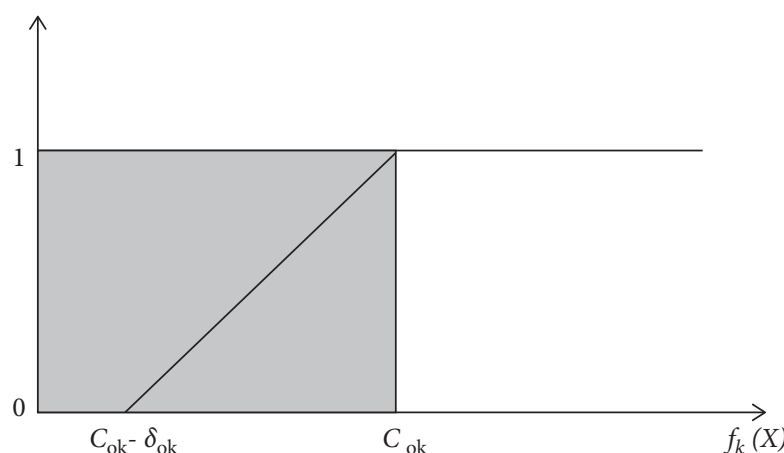

Figure 2: Membership function curve.

single-objective nonlinear problem. The mathematical model is as follows:

$$
\left\{\begin{array}{l}
\max \lambda \\
f_{1}(X)-\delta_{01} \lambda \geq c_{01}-\delta_{01}, \\
\cdots \\
f_{k}(X)-\delta_{0 k} \lambda \geq c_{0 k}-\delta_{0 k}, \\
\cdots \\
f_{p}(X)-\delta_{0 p} \lambda \geq c_{0 p}-\delta_{0 p} \\
0 \leq \lambda \leq 1, \\
g_{i}(X) \leq 0, i=1,2, \ldots, m, \\
h_{j}(X)=0, j=1,2, \ldots, l
\end{array}\right.
$$

Step 6. The wireless communication network algorithm is applied to solve the previously mentioned singleobjective fuzzy optimization model and find the optimal value of each objective function under a given satisfaction degree (90\%).

3.2. Problem Solving for Half Constrained Flow Network. The personnel on branches 3, 4, and 7 are known to be $18.00 \mathrm{~m}^{3} / \mathrm{s}, 20.00 \mathrm{~m}^{3} / \mathrm{s}$, and $35.00 \mathrm{~m}^{3} / \mathrm{s}$, and a new matrix $a_{i j}$ can be obtained.

$$
a_{i j}=\left[\begin{array}{ccccccccc}
1 & 2 & 3 & 4 & 5 & 6 & 6 & 8 & 9 \\
-1 & 1 & 0 & 1 & 0 & 1 & 0 & 0 & 0 \\
1 & -1 & 1 & 0 & -1 & 0 & 0 & 0 & 0 \\
0 & 1 & 0 & 0 & 0 & 0 & 1 & 0 & 0 \\
1 & 0 & 0 & 0 & 0 & 1 & 0 & 1 & 0
\end{array}\right] .
$$

We define the personnel of branches 7 and 8 as surface personnel and branch 5 as a candidate for underground personnel. The objective function is

$$
\min Z=Q_{5} H F_{5}+a H F_{7}+Q_{8} H F_{8} .
$$

Suppose $Z_{1}=\left(Q_{i}+H F_{8}\right) / 2, \quad Z_{2}=\left(Q_{8}-H F_{8}\right) / 2$ and then introduce nonnegative special variables $\lambda_{k}, u_{k}$, and $v_{k}$, so that $\sum_{k} \lambda_{k}=0, \sum_{k} u_{k}=0, \sum_{k} v_{k}=0$. Then, $Z_{1}, Z_{2}$, and $Q_{8}$ can be expressed as $Q_{8}=\sum_{K} \lambda_{k} Q_{8 k}, Z_{1}=\sum_{k} u_{k} Z_{1 k}$,
$Z_{2}=\sum_{k} v_{k} Z_{2 k}$. Then, the previously mentioned problem can be transformed into linear programming, and its objective function is

$$
\min Z=Q_{5} H F_{5}+Q_{7} H F_{7}+\sum_{k} u_{k} Z_{1 k}^{2}-\sum_{k} v_{k} Z_{2 k}^{2}
$$

After calculation, the wind pressure on branch 7 is 840.88 $\mathrm{Pa}$, the wind pressure shared by branch 8 is $113.6 \mathrm{~Pa}$, and the wind pressure on branch 5 is $374.35 \mathrm{~Pa}$.

\section{The Basic Function and Innovation of the Cost Control System for Mining Personnel}

A simulation model of the mine's in-pit visual production system is built according to the actual situation of the specific mine at first, and simulation operation is performed after the model is verified and confirmed. The in-pit production process is observed dynamically in the mine. In addition, the operating status of each stage of the biological flow system of mine can be analyzed in real time. The development logic program of the dynamic optimization policy decision system for the three-dimensional dynamic visualization of underground mine engineering is as follows $[11,12]$.

(1) Information about mine production systems is collected for specific mines. It contains the parameters related to the tunnel formation system: the logistics process, production capacity, and technical parameters and capabilities of related equipment in the production system of coal mining, ventilation, transportation, drainage, and so on.

(2) Statistical analysis and integration is performed for the previously mentioned collected data related to the cost control system for underground mining personnel.

(3) Analyze the various influencing factors of mine production, define the boundaries of the mine logistics system, and divide the subsystems according to the functions of the logistics process of mine.

(4) On the basis of a large number of field investigations and statistical analysis, the statistical rules and parameters of each part of the mining system are determined.

(5) Through the mine layout system and production system of the built mine, the connection and conversion relationship between the various subsystems of the mine production is found out, the integration capability of the various equipment of the mine production system and the logistics system is established, and a fully visualized underground mine model of mining personnel cost control system is built.

(6) According to the simulation software of WITNESS, the cost control system model of the underground mining personnel of the mine is reasonably converted into a computer simulation model. 
(7) The reliability simulation of the simulation model was verified, the interference of random factors was eliminated, the simulation results were statistically analyzed, and unreasonable factors in the system were found.

(8) The model is improved to make it more in line with the actual mine production system.

(9) According to the actual production of mine, the simulation operation of the mine logistics system is carried out. According to the simulation results, the mine logistics system is rationally optimized and integrated, to apply the improvement plan to the mine production practice and compare the improved demonstration operation result with the actual mine production practice effect for evaluation.

Among them, the key issues in the development of the mining personnel cost control system are as follows.

(1) Collect true information about mine production systems for specific mines: the parameters of the tunnel configuration system, coal mining, excavation, ventilation, transportation, drainage, and other logistics process, production capacity, and technical parameters and capabilities of related equipment

(2) Import mine development engineering drawings (Figure 3) into the WITNESS system. The imported engineering drawings will be imported to the prebuilt system modules based on the actual underground mining personnel cost control system process (Figure 4: the mine underground mining personnel cost control system process) to build a simulation model of the mine's in-pit visual production system.

(3) Perform the validity check of the simulation model of the in-pit visual production system in the mine. Transform the parameters of field survey and statistical analysis (including technical indicators such as underground logistics equipment capability, failure rate, repair rate, and other reliability indicators) into computer simulation models. Carry out simulation operation, analyze it combined with the actual logistics system operation, carry out validity check, and ensure the validity of the simulation system.

\section{Realization of Cost Control of Mining Personnel}

5.1. Projective Transformation. The functions of the wireless communication network-like calculation procedure library cannot directly generate arc surfaces. If the NURBS surface adopted cannot be correctly controlled, it cannot meet the need of explaining the lane. In addition, the complicated program leads to the low operation efficiency. In this study, an arched lane is made by adding a tangent plane. The arched lane is composed of two concentric cylinders with different radii and two concentric circular plates. Projective transformation is an important graphics conversion technique

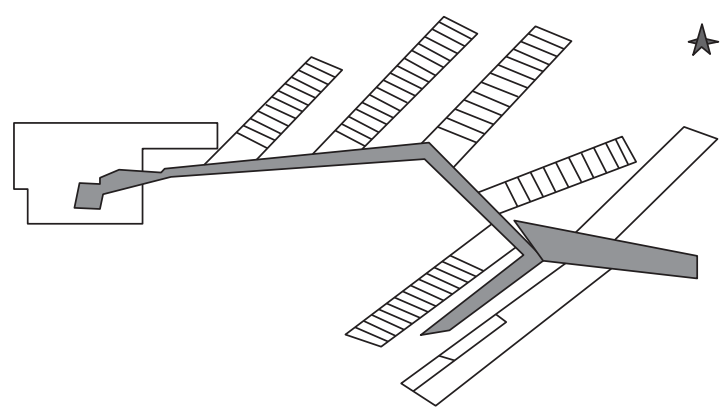

Figure 3: Mine development engineering drawing (partial).

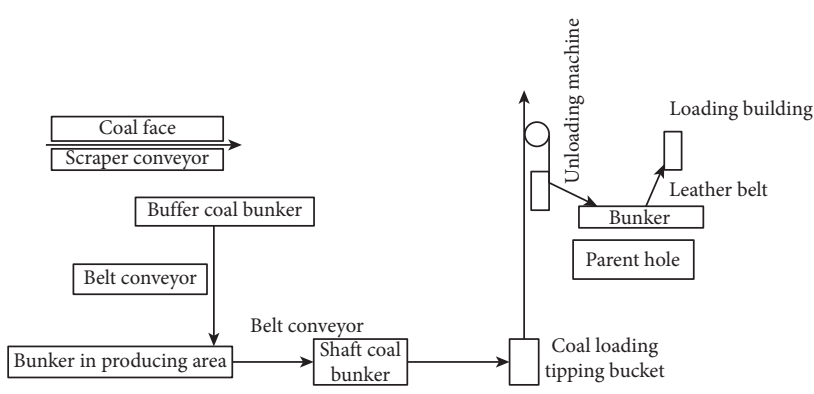

FIGURE 4: The process of the cost control system for underground mining personnel.

whose purpose is to define the view. The extra part outside the field of view is intercepted, and the final image is only the relevant part of the visual field.

In perspective projection, the projection close to the point is very large, the projection from the viewpoint is very small, and the projection that reaches the extreme point disappears and becomes the vanishing point. The projection is mainly used for meeting animation requests, visualization and other image display areas. In the mine mining intelligent analysis system, the proportional relationship between the alleys remains unchanged after the projection transformation for a more reasonable use of the relative spatial positions of different projects for the mining project layout of the mine.

5.2. Illumination Treatment. The illumination model of the algorithm is, for example, wireless communication network, radiation, ambient light, diffused light, specular light, and so on. The radiation is emitted directly from the object and is not affected by the light source. Ambient light is scattered multiple times from the light source through the environment, and light that cannot determine its direction is considered to come from all directions. The diffused light comes from a certain direction. It is brighter when it is perpendicular to the object than when it is tilted. After irradiating the object, it will be distributed evenly in all directions. Specular light comes from a specific direction and reflects in other directions.

The purpose of the illumination model is to make the generated graphic image be truly felt by performing complex calculations on normal, light sources, materials, and so on. The command to start the illumination model is glEnbale. 
LIGHTING), gDiscable (GL_LIGHTING) turn off the current light.

5.3. Plane Normal Vector. The calculation vector strictly represents the direction between multiple countries. Open GL needs to use the normal vector to calculate the angle of light irradiating the object. In order to generate a threedimensional image, the normal vector of the object must be defined. The wireless communication network algorithm uses two functions to define the normal vector. The first function means the three component values of the normal vector, respectively, given by the function. Second, define a pointer with three elements. The wireless communication network does not provide a function of the corona calculation method. Therefore, it is necessary to create a corresponding program for the developer. The normal vector algorithm designed in this research is verified by actual data and is accurate and effective.

5.4. Integrated Implementation. The characteristics of the following aspects are mainly reflected in the research and development process.

(1) In order to facilitate the development and use, this system adopts a modular design concept to construct a three-dimensional dynamic visualization system and related equipment modules for the engineering in the pit. Using this modular structure, different mines can be constructed: underground laborers and three-dimensional dynamic visualization simulation to determine the needs of the system.

(2) Regarding the logistics process and flow of the simulation system model, in the CAD engineering drawing of the actual mine production system, such as the introduction of mine development and mining plan, the structure configuration and construction of the simulation system can be fully adapted to the actual system (Table 2).

\section{Examples and Results of the Analysis}

Miner cost control is one of the important tasks of mining production. Through more accurate miner cost forecasting and control, parameters and mining parameters of the mine blocks are adjusted economically and reasonably, the personnel are arranged, and the personnel costs are reduced to improve results and benefits. The cost of mining personnel is closely related to the entire mining system and is affected by ventilation, drainage, transportation, and mining processes. The factors that affect the cost of mining personnel interact in a complex manner. Due to the complexity of the system, it is difficult to use traditional methods to build accurate and complete prediction and control models.

6.1. Mining Equipment. The equipment used in the mine development includes powdered ammonium nitrate explosive, light oil, detonating cords, explosive tubes, and detonators. The prices are shown in Table 3.
6.2. Mining Technology. When mining, the parameters of the mining process mainly include explosive unit consumption, row spacing, hole bottom distance, and collapse steps. Based on the theoretical and experimental research on the blastability evaluation of metal ore and the optimization of deep hole excavation parameters of the in-pit excavation sites, these parameters need to be considered in the optimal control model of production.

6.2.1. Preliminary Determination of Explosive Unit Consumption. All test blast holes are artificially filled. According to relevant data and experience, the unit consumption $\mathrm{q}$ value of the funnel test explosive is taken as $3.25 \mathrm{~kg} / \mathrm{m}^{3}$ and detonated at the bottom of the hole with an explosive tube detonator. After the explosive is filled, it will be severely blocked by taphole clay. After the blast hole is mined, the falling part of the laccolith around the funnel mouth is subtracted to determine the boundary of the funnel mouth. Take the blast hole as the center, take the radii $r$ of nine funnels in different directions directly at $45^{\circ}$, use the average value as the radius $r$ of the collecting funnel, to measure the actual minimum resistance cord $w$, and calculate the mining action index $n$. The funnel test data based on test statistics and calculation benchmarks are shown in Table 4 .

The average radius $r$ of the mining funnel obtained from Table 4 is $0.88 \mathrm{~m}$, the average minimum resistance cord is $0.65 \mathrm{~m}$, and the actual mining action index $n=r / w=1.38$. The explosive consumption q value in actual standard unit is in turn calculated as $1.68 \mathrm{~kg} / \mathrm{m}^{3}$ according to the formula of Polis Aube.

The number of columns in each unit consumption value experiment is all 10 columns, and the number of tests is four times. The number of columns corresponding to each detonation is two columns, two columns, three columns, and three columns. The detonation is delayed in milliseconds between the columns, and the time interval should not be less than $50 \mathrm{~ms}$. Table 5 shows the mining test results when different explosives are consumed separately.

Synthesizing the analysis and summary of the mining effect of multiple experiments, the reasonable unit consumption range of the mining area is $0.82-0.88 \mathrm{~km} / \mathrm{m}^{3}$, and the unit consumption value is set to $0.86 \mathrm{~km} / \mathrm{m}^{3}$ in the mining design. The actual unit consumption is controlled within the range of $0.82-088 \mathrm{~kg} / \mathrm{m}^{3}$. The effect after mining is ideal, and the volume fraction is low (3\%-25\%). Afterwards, its impact on the construction is very small.

6.2.2. Selection of the Distance between the Row Spacing of Fan-Shaped Deep Hole and the Hole Bottom. In the collapse of mining place, the interval between the fan-shaped deep holes is the minimum resistance line, which is usually determined by the diameter of the hole, the characteristics of the ore, the power of the explosive, and the degree of rock fragmentation. The distance between the bottom of the hole is the vertical distance between relatively shallow hole bottom and the deep blast holes. The blast hole density factor is the ratio of the bottom hole distance to the minimum resistance line, that is, 
TABLE 2: The modular structure of cost control for mining personnel.

\begin{tabular}{|c|c|c|c|}
\hline $\begin{array}{l}\text { Serial } \\
\text { number }\end{array}$ & Module name & Module content & Module role \\
\hline 1 & Mining equipment & Shearers, supports, roadheader, etc. & $\begin{array}{c}\text { Used for selection and layout of } \\
\text { equipment }\end{array}$ \\
\hline 2 & Transportation equipment & $\begin{array}{c}\text { Mine carts, belt conveyors, transfer conveyor, mine carts } \\
\text { tippers, scraper conveyors, etc. }\end{array}$ & \\
\hline 3 & Lifting equipment & Main and auxiliary shaft hoists, cages, small winches, etc. & \\
\hline 4 & Ventilation equipment & Fans, dampers, air ducts, etc. & \\
\hline 5 & Drainage equipment & Water pump, pipeline, drain, sump pit & \\
\hline 6 & Underground personnel & $\begin{array}{l}\text { Coal mining, tunneling, support personnel, maintenance } \\
\text { personnel, management personnel, etc. }\end{array}$ & For personnel management \\
\hline 7 & Laneway & $\begin{array}{l}\text { Horizontal main alley, underground parking lot, } \\
\text { transportation main alley, transportation dip entry, } \\
\text { crossheading, etc. }\end{array}$ & $\begin{array}{l}\text { Used for 3D dynamic visualization } \\
\text { of underground engineering }\end{array}$ \\
\hline 8 & Underground chamber & Coal bunker, gangue bunker, etc. & System layout \\
\hline 9 & Main and auxiliary shaft & Main shaft, auxiliary shaft, air shaft & \\
\hline 10 & Coal face & Comprehensive mining, general mining, etc. & Selection of coal mining method \\
\hline 11 & Face of heading & Comprehensive mining, general mining, etc. & Selection of tunneling methods \\
\hline 12 & Support module & Working face support module, laneway support module & Selection of support mode \\
\hline 13 & $\begin{array}{l}\text { Mine production cycle } \\
\text { operation module }\end{array}$ & $\begin{array}{c}\text { Cycle operations of coal mining, tunneling, auxiliary } \\
\text { production, etc. }\end{array}$ & Selection of work organization form \\
\hline 14 & Mine excavation plan & $\begin{array}{l}\text { Layout drawing of underground mining, layout drawing of } \\
\text { mining work surface, etc. }\end{array}$ & $\begin{array}{c}\text { Base map of the simulation system } \\
\text { layout }\end{array}$ \\
\hline 15 & CAD module & CAD system, CAD library & Import and draw CAD drawings \\
\hline 16 & JMP analysis module & System reliability analysis indicators, etc. & Analyze the reliability of the system \\
\hline 17 & Auxiliary function & System maintenance and other module & $\begin{array}{l}\text { Other auxiliary functions of the } \\
\text { supplementary system }\end{array}$ \\
\hline
\end{tabular}

TABle 3: Prices of mining equipment.

\begin{tabular}{lcc}
\hline Composition & Price & Average price \\
\hline Powdery ammonium nitrate explosive/(yuan/t) & $4700 \sim 7000$ & 5500 \\
Diesel/(yuan/L) & $709 \sim 760$ & 728 \\
Detonating cord/(yuan/m) & $51 \sim 59$ & 55 \\
Nonel/(yuan/m) & $10 \sim 16$ & 126 \\
Detonator/(yuan/send) & $84 \sim 94$ & 87 \\
\hline
\end{tabular}

TABLE 4: Mining funnel test parameters.

\begin{tabular}{|c|c|c|c|c|c|c|c|c|}
\hline $\begin{array}{l}\text { Blast hole } \\
\text { number }\end{array}$ & $\begin{array}{l}\text { Explosion } \\
\text { load }(\mathrm{kg})\end{array}$ & $\begin{array}{c}\text { Loaded } \\
\text { length }(\mathrm{m})\end{array}$ & $\begin{array}{l}\text { Blockage } \\
\text { length }(\mathrm{m})\end{array}$ & $\begin{array}{c}\text { Funnel } \\
\text { radius }(\mathrm{m})\end{array}$ & $\begin{array}{l}\text { Design minimum } \\
\text { resistance line }(\mathrm{m})\end{array}$ & $\begin{array}{l}\text { Actual minimum } \\
\text { resistance line }\end{array}$ & $\begin{array}{c}\text { Mining effect } \\
\text { evaluation }\end{array}$ & $\begin{array}{c}\text { Data } \\
\text { selection }\end{array}$ \\
\hline 1 & 087 & 04 & 05 & 084 & 065 & 066 & $\begin{array}{c}\text { Uniform } \\
\text { lumpiness }\end{array}$ & Reserve \\
\hline 2 & 087 & 04 & 05 & 088 & 065 & 068 & $\begin{array}{l}\text { Uniform } \\
\text { lumpiness }\end{array}$ & Reserve \\
\hline 3 & 087 & 04 & 05 & - & 065 & - & Rushing stone & Reject \\
\hline 4 & 087 & 04 & 05 & 085 & 065 & 062 & $\begin{array}{l}\text { Uniform } \\
\text { lumpiness }\end{array}$ & Reserve \\
\hline 5 & 087 & 04 & 05 & 074 & 065 & 073 & Size of lump & Reject \\
\hline 6 & 087 & 04 & 05 & 118 & 065 & 055 & $\begin{array}{l}\text { Many chunk } \\
\text { and fragment }\end{array}$ & Reject \\
\hline
\end{tabular}

$$
m=\frac{a}{w}
$$

where $m$ is the blast hole density coefficient; $A$ is the bottom hole distance, $m ; w$ is the selection of the minimum resistance line.
The three parameters $m, a$, and $w$ directly determine the hole density of the blast hole. The minimum resistance line reflects the density of the hole web between columns, and the bottom hole distance reflects the hole web density of the deep holes in the column, and the blast hole density coefficient reflects their mutual relationship. Whether the 
TABLE 5: Mining test results of different explosive unit consumption.

\begin{tabular}{|c|c|c|c|c|c|c|c|}
\hline $\begin{array}{l}\text { Unit } \\
\text { consumption } / \mathrm{kg} / \\
\mathrm{m} 3\end{array}$ & $\begin{array}{c}\text { Row } \\
\text { spacing } \\
(\mathrm{m})\end{array}$ & $\begin{array}{l}\text { Hole bottom } \\
\text { distance }(\mathrm{m})\end{array}$ & Mining effect & $\begin{array}{l}\text { Open wiring } \\
\text { condition }\end{array}$ & $\begin{array}{l}\text { Top board } \\
\text { situation }\end{array}$ & $\begin{array}{l}\text { Two side- } \\
\text { wall } \\
\text { situation } \\
\end{array}$ & $\begin{array}{l}\text { Rear blast hole } \\
\text { situation }\end{array}$ \\
\hline 091-095 & 16 & 20 & Overgrind of ore & $\begin{array}{l}\text { Damaged } \\
\text { severely }\end{array}$ & $\begin{array}{l}\text { Lots of falling } \\
\text { lumps and } \\
\text { pumice }\end{array}$ & $\begin{array}{c}\text { More } \\
\text { slanting side- } \\
\text { wall }\end{array}$ & $\begin{array}{l}\text { Serious blocking of } \\
\text { holes and dislocation }\end{array}$ \\
\hline 086-091 & 16 & 20 & $\begin{array}{l}\text { Small lumpiness, } \\
\text { partly fine ore }\end{array}$ & Small damage & More pumice & $\begin{array}{l}\text { Less slanting } \\
\text { side-wall }\end{array}$ & $\begin{array}{l}\text { More plugged holes, } \\
\text { less dislocation }\end{array}$ \\
\hline $082-086$ & 16 & 20 & $\begin{array}{l}\text { Uniform } \\
\text { lumpiness, less } \\
\text { fine ore }\end{array}$ & Less damage & $\begin{array}{l}\text { Partial pumice } \\
\text { and falling } \\
\text { lumps }\end{array}$ & $\begin{array}{l}\text { Less slanting } \\
\text { side-wall }\end{array}$ & $\begin{array}{l}\text { Less plugged holes } \\
\text { and dislocation }\end{array}$ \\
\hline 075-082 & 16 & 20 & $\begin{array}{l}\text { Uneven } \\
\text { lumpiness, high } \\
\text { lump rate }\end{array}$ & Less damage & $\begin{array}{l}\text { Less pumice } \\
\text { and falling } \\
\text { lumps }\end{array}$ & $\begin{array}{c}\text { Rarely } \\
\text { slanting side- } \\
\text { wall }\end{array}$ & $\begin{array}{l}\text { Occasionally plugged } \\
\text { or misplaced }\end{array}$ \\
\hline
\end{tabular}

selection of these three parameters is correct will directly affect the economic and technical indicators in the mining process.

Combining the experience of various metallurgical mines, the blast hole density coefficient can be $m=1.0 \sim 2.0$. The relationship between the minimum resistance line $w$ and the blast hole diameter $d$ can be selected for reference from the actual data of the relevant mine. The value of the minimum resistance line used in mines is roughly as shown in Table 6 [13-15].

After the previously mentioned analysis, the design unit consumption is $0.85 \mathrm{~kg} / \mathrm{m}^{3}$, and the actual unit consumption is mining tests with different distances and intervals in the range of $082-087 \mathrm{~kg} / \mathrm{m}^{3}$. In the test, the hole bottom distances are divided into five groups, namely, $1.8 \mathrm{~m}, 2 \mathrm{~m}$, $2.3 \mathrm{~m}, 2.4 \mathrm{~m}$, and $2.5 \mathrm{~m}$, respectively. Each group corresponds to seven kinds of intervals, $14 \mathrm{~m}, 15 \mathrm{~m}, 16 \mathrm{~m}, 18 \mathrm{~m}$, $19 \mathrm{~m}, 20 \mathrm{~m}$, and $21 \mathrm{~m}$, respectively. The test site is located on the 2280 floor on the reexcavation channel of no. 23-25 detection line and the no. 19 detection line. Part of it is arranged on the return way of the no. 19 exploration line on the 2265 floor.

After mining, the mining effect records and analysis of seven different intervals are performed corresponding to five different hole bottom spacings. As the hole bottom distance and discharge interval increase, the impact of front row mining on the rear row of blast holes becomes more and more serious. The blast holes in the back row are blocked and misaligned more and more. The destruction of the eyebrow line gradually became apparent. The ceiling and the two groups will also be increased if they are missing. Obviously, the progress of the next mining project has slowed down. In the case of a certain hole bottom distance, as the cannon hole density coefficient increases, the volume rate after mining gradually decreases. If the big blast hole density coefficient increases to a certain range, a larger volume rate will be maintained. The relationship is shown in Figure 5.

Considering the comprehensive mining effect and project progress, the reasonable row spacing is 1.6-1.8 meters, and the reasonable hole bottom distance is $2-22$ meters.
6.2.3. Determination of the Step Pitch of Ore Caving. According to the results of multiple mining tests and the determination of the loss of ore drawing poverty, if two roads are used for collapsed mines simultaneously, the step distance of collapsed mines should preferably be three rows in each direction; that is, the stepped distance of collapsed mines is about $53 \mathrm{~m}$. When a one-way road falls into a mine, the collapsed mines steps are preferably four columns per road. In other words, the collapsed mine step is about 7 meters.

Through a large number of field mining tests, mining parameters can be selected from Table 7 .

\subsection{Design of Wireless Communication Network.} Compare the ratio of the amount of ore mined at one time to the cost of material used for mining $1 \mathrm{~m}^{3}$. The price performance ratio is considered as a measurement index, and cost performance is used as the output point of the model. In this way, the cost of equipment and personnel required for the volume of ore of the mining unit and the mining parameters are considered as the influencing factors of the system. This neural network model has nine input nodes. Influence. In other words, the model has nine input nodes. Due to the cost performance as the output of the model, the model has only one output node.

We collected a total of 20 learning samples, as shown in Table 8.

The first nine items in Table 6 are the input factors of the learning sample, and the last item is the output quantity. Use the samples in Table 8 to train the network. Before training, you should normalize the data not in $[0,1]$.

The model training, prediction, and appropriate program design calculations are carried out,. The model accuracy during training is 0.001 , and the learning step is selected as 0.05 . After 17 repetitions, the accuracy reached the requirement and the training was completed. Figure 6 shows the error variance curve during model training. At this point, the connection weight of each node of the model has been determined. The same type of samples can be predicted at any time.

According to the range of mining equipment and mining process parameters, each element of the model is valued 
TABLE 6: Correspondence table of the relationship between the minimum resistance wire and the diameter of the blast hole.

\begin{tabular}{lccc}
\hline Blast hole diameter $(\mathrm{mm})$ & Minimum resistance line $(\mathrm{m})$ & Blast hole diameter $(\mathrm{mm})$ & Minimum resistance line $(\mathrm{m})$ \\
\hline $50-60$ & $12-17$ & $60-85$ & $18-28$ \\
$60-70$ & $15-22$ & $90-125$ & $26-45$ \\
\hline
\end{tabular}

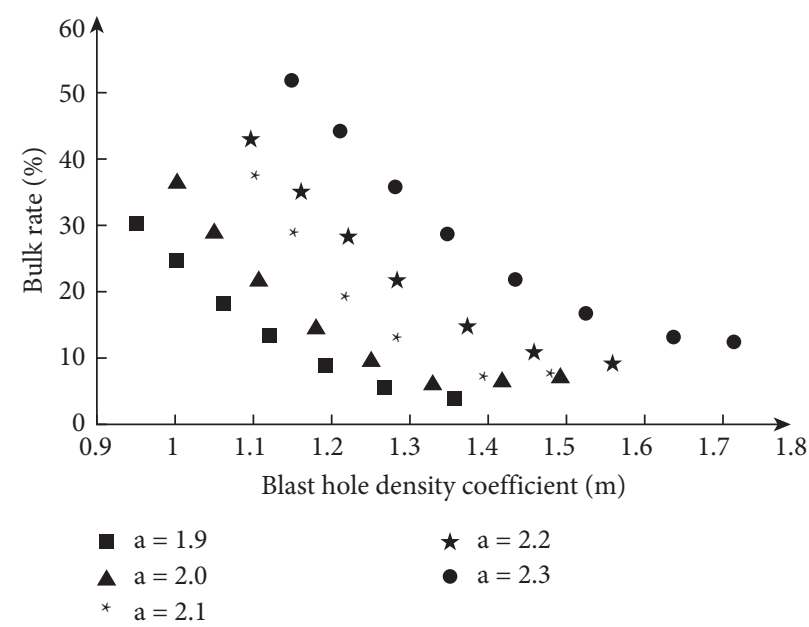

FIGURE 5: The relationship charts between the blast hole density coefficient and the yield rate of large lumps.

TABLE 7: Mining parameters.

Mining parameters Explosive unit consumption $/\left(\mathrm{kg} / \mathrm{m}^{3}\right)$ Row spacing $(\mathrm{m})$ Hole bottom distance (m) Ore drawing step pitch $/ \mathrm{row}$ Parameter value $0.83 \sim 0.873$ $5 \sim 1.9$ $1.8 \sim 24$ $2 \sim 5$

TABLE 8: Learning sample.

\begin{tabular}{|c|c|c|c|c|c|c|c|c|c|}
\hline \multicolumn{5}{|c|}{ Mining unit volume of ore mining equipment consumption } & \multicolumn{4}{|c|}{ Operational parameter } & \multirow[b]{2}{*}{$\begin{array}{c}\text { Performance } \\
\text { price ratio } /\left(\mathrm{m}^{3} /\right. \\
\text { yuan })\end{array}$} \\
\hline $\begin{array}{l}\text { Powdery } \\
\text { ammonia } \\
\text { dynamite/ } \\
\left(\text { yuan } / \mathrm{m}^{3} \text { ) }\right.\end{array}$ & $\begin{array}{c}\text { Diesel/ } \\
\text { (yuan/ } \\
\mathrm{m}^{3} \text { ) }\end{array}$ & $\begin{array}{c}\text { Detonating } \\
\text { cord/(yuan/ } \\
\left.\mathrm{m}^{3}\right)\end{array}$ & $\begin{array}{c}\text { Nonel/ } \\
(\text { yuan/ } \\
\mathrm{m}^{3} \text { ) }\end{array}$ & $\begin{array}{c}\text { Detonator/ } \\
\left(\mathrm{kg} / \mathrm{m}^{3}\right)\end{array}$ & $\begin{array}{l}\text { Explosive unit } \\
\text { consumption/ } \\
\left(\mathrm{kg} / \mathrm{m}^{3}\right)\end{array}$ & $\begin{array}{c}\text { Row } \\
\text { spacing/ } \\
\text { m }\end{array}$ & $\begin{array}{c}\text { Hole } \\
\text { bottom } \\
\text { distance/ } \\
\text { m }\end{array}$ & $\begin{array}{c}\text { Ore } \\
\text { drawing } \\
\text { step pitch/ } \\
\text { row }\end{array}$ & \\
\hline 457 & 50 & 235 & 39 & 53 & 85 & 170 & 20 & 4 & 2672 \\
\hline 435 & 48 & 224 & 3 & 42 & 82 & 172 & 21 & 4 & 3128 \\
\hline 459 & 49 & 228 & 32 & 45 & 85 & 172 & 20 & 2 & 2693 \\
\hline 471 & 51 & 265 & 33 & 46 & 87 & 16 & 19 & 2 & 250 \\
\hline 444 & 48 & 225 & 30 & 41 & 82 & 166 & 21 & 3 & 307 \\
\hline 453 & 49 & 235 & 34 & 48 & 84 & 171 & 20 & 2 & 2579 \\
\hline 464 & 50 & 230 & 33 & 46 & 86 & 171 & 22 & 4 & 2930 \\
\hline 455 & 49 & 228 & 36 & 50 & 84 & 169 & 19 & 3 & 2155 \\
\hline 449 & 48 & 217 & 34 & 47 & 83 & 178 & 22 & 2 & 2740 \\
\hline 463 & 50 & 228 & 31 & 43 & 86 & 168 & 21 & 3 & 2832 \\
\hline 451 & 47 & 223 & 30 & 42 & 83 & 176 & 20 & 2 & 2809 \\
\hline 463 & 50 & 240 & 31 & 44 & 86 & 171 & 22 & 3 & 3224 \\
\hline 464 & 50 & 226 & 38 & 44 & 86 & 177 & 21 & 3 & 3672 \\
\hline 454 & 49 & 236 & 29 & 41 & 84 & 164 & 21 & 4 & 3079 \\
\hline 460 & 46 & 215 & 32 & 42 & 85 & 176 & 21 & 3 & 3284 \\
\hline 455 & 49 & 238 & 33 & 45 & 84 & 19 & 22 & 3 & 2915 \\
\hline 461 & 50 & 246 & 31 & 43 & 85 & 178 & 22 & 3 & 3332 \\
\hline 460 & 49 & 244 & 34 & 47 & 85 & 167 & 2 & 4 & 2816 \\
\hline 447 & 48 & 237 & 29 & 41 & 83 & 166 & 21 & 4 & 3556 \\
\hline 445 & 49 & 225 & 31 & 43 & 82 & 173 & 21 & 2 & 3166 \\
\hline
\end{tabular}




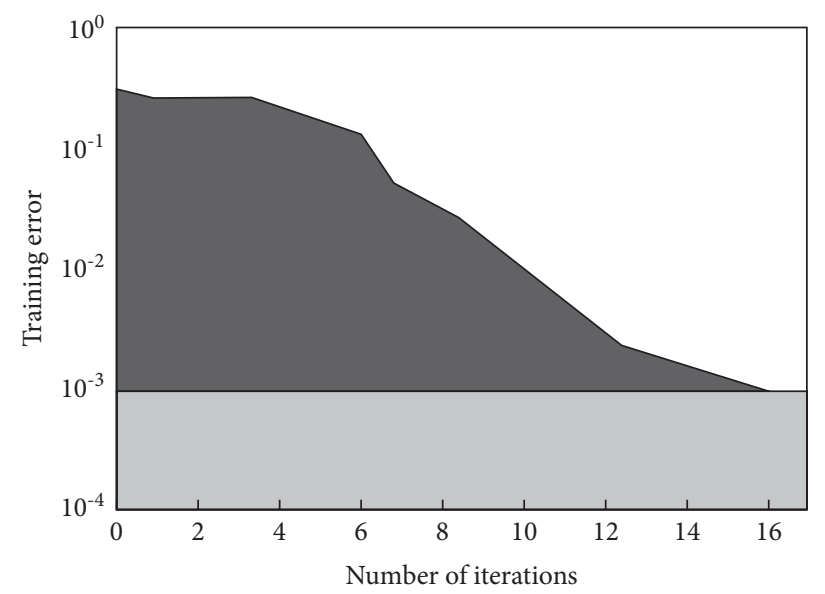

FiguRE 6: Training error curve.

TABle 9: Model prediction results.

\begin{tabular}{|c|c|c|c|c|c|c|c|c|c|c|c|}
\hline \multirow[b]{2}{*}{ Number } & \multicolumn{5}{|c|}{$\begin{array}{l}\text { Mining unit volume of ore mining equipment } \\
\text { consumption }\end{array}$} & \multicolumn{4}{|c|}{ Production process parameters } & \multicolumn{2}{|c|}{$\begin{array}{l}\text { Performance } \\
\text { price ratio }\end{array}$} \\
\hline & $\begin{array}{l}\text { Powdery } \\
\text { ammonium } \\
\text { nitrate/ } \\
\left(\text { yuan } / \mathrm{m}^{3} \text { ) }\right.\end{array}$ & $\begin{array}{c}\text { Diesel/ } \\
(\text { yuan/ } \\
\mathrm{m}^{3} \text { ) }\end{array}$ & $\begin{array}{c}\text { Detonating } \\
\text { cord/(yuan/ } \\
\mathrm{m}^{3} \text { ) }\end{array}$ & $\begin{array}{c}\text { Nonel/ } \\
(\text { yuan/ } \\
\mathrm{m}^{3} \text { ) }\end{array}$ & $\begin{array}{c}\text { Detonator/ } \\
\left(\mathrm{kg} / \mathrm{m}^{3}\right)\end{array}$ & $\begin{array}{l}\text { Explosive unit } \\
\text { consumption/ } \\
\left(\mathrm{kg} / \mathrm{m}^{3}\right)\end{array}$ & $\begin{array}{c}\text { Row } \\
\text { spacing/ } \\
\text { m }\end{array}$ & $\begin{array}{c}\text { Hole } \\
\text { bottom } \\
\text { distance/ } \\
\mathrm{m}\end{array}$ & $\begin{array}{c}\text { Ore } \\
\text { drawing } \\
\text { step } \\
\text { pitch/ } \\
\text { row }\end{array}$ & Predicted & Actual \\
\hline 1 & 459 & 51 & 241 & 40 & 53 & 86 & 161 & 21 & 5 & 2735 & 2690 \\
\hline 2 & 459 & 48 & 223 & 31 & 41 & 85 & 170 & 21 & 3 & 3023 & 3071 \\
\hline 3 & 459 & 48 & 228 & 33 & 45 & 86 & 176 & 22 & 4 & 3293 & 3374 \\
\hline 4 & 459 & 49 & 230 & 35 & 43 & 85 & 165 & 21 & 3 & 3123 & 3141 \\
\hline 5 & 471 & 49 & 238 & 34 & 46 & 88 & 176 & 22 & 4 & 3009 & 3034 \\
\hline 6 & 464 & 51 & 264 & 33 & 45 & 86 & 18 & 22 & 4 & 3021 & 2993 \\
\hline 7 & 470 & 48 & 224 & 30 & 40 & 87 & 155 & 22 & 4 & 336 & 3357 \\
\hline
\end{tabular}

using interval intensive scanning technology in turn, which is used as the prediction sample of the model. Due to the large number of input factors and prediction samples, in order to ensure the comprehensiveness of the prediction samples, a computer is used to obtain values for the nine elements in sequence. Unsolicited data is automatically deleted. The selected prediction samples can be directly input into the model for prediction, and the performance-toprice ratio of all prediction samples can be obtained. Table 9 shows the results of the inverse normalization after the prediction of the seven groups of prediction samples of the model.

According to the prediction results in Table 9, the deviation between the prediction and the actual situation is relatively small, and the prediction and actual results of the third and seventh groups are relatively high. Multiple production practices and wireless communication networks are combined to predict and control the cost of miners. This lead mine uses the best mining parameter values of the collapse method without sill pillar division. The explosive unit consumption is $0.87 \mathrm{~kg} / \mathrm{m}^{3}$, the row spacing is $1.76 \mathrm{~m}$, the hole bottom distance is $2.2 \mathrm{~m}$, and the collapse step is $5.26 \mathrm{~m}$. At this time, the actual price ratio of development reaches 33.78/yuan, which meets the production requirements.

\section{Conclusions}

In this paper, experiments on the budget and control of the cost of mining workers by wireless communication network technology have been carried out to prove that the characteristics of sandstone deposits are used to optimize the data, and the budget and control model of the cost of mining workers through wireless communication network technology are summarized. The method can accurately improve the mining work, guide the new direction of the mining design work, and provide favorable experience and data for mining similar mines.

\section{Data Availability}

The labeled datasets used to support the findings of this study are available from the corresponding author upon request. 


\section{Conflicts of Interest}

The authors declare no conflicts of interest.

\section{Acknowledgments}

This study was sponsored by Liaoning Technical University.

\section{References}

[1] W. Yang, Z. Ai, X. Zhang, R. Gou, and X. Chang, "Nonlinear three-dimensional dynamics of a marine viscoelastic riser subjected to uniform flow," Ocean Engineering, vol. 149, no. 1, pp. 38-52, 2018.

[2] I. D. Moore and F. Guan, "Three-dimensional dynamic response of lined tunnels due to incident seismic waves," Earthquake Engineering \& Structural Dynamics, vol. 25, no. 4, pp. 357-369, 2015.

[3] Y. Liu, Z. Wu, Q. Yang, and K. Leng, "Dynamic stability evaluation of underground tunnels based on deformation reinforcement theory," Advances in Engineering Software, vol. 124, pp. 97-108, 2018.

[4] D. Conroy and O. K. Matar, "Dynamics and stability of threedimensional ferrofluid films in a magnetic field," Journal of Engineering Mathematics, vol. 107, no. 1, pp. 253-268, 2017.

[5] Y. Liang and Q. Liu, "Early warning and real-time control of construction safety risk of underground engineering based on building information modeling and internet of things," Neural Computing and Applications, pp. 1-10, 2021.

[6] S. A. Ghoreishi-Madiseh, A. P. Sasmito, F. P. Hassani, and L. Amiri, "Performance evaluation of large scale rock-pit seasonal thermal energy storage for application in underground mine ventilation," Applied Energy, vol. 185, no. 2, pp. 1940-1947, 2016.

[7] Z.-z. Liu, P. Cao, H. Lin, J.-J. Meng, and Y.-X. Wang, "Threedimensional upper bound limit analysis of underground cavities using nonlinear baker failure criterion," Transactions of Nonferrous Metals Society of China, vol. 30, no. 7, pp. 1916-1927, 2020.

[8] P. Shan and W. Sun, "Analysis of thermal effect around an underground storage cavern with a combined three-dimensional indirect boundary element method," Engineering Analysis with Boundary Elements, vol. 95, no. OCT, pp. 255-265, 2018.

[9] D. S. S. Sandanayake, E. Topal, and M. W. Ali Asad, "A heuristic approach to optimal design of an underground mine stope layout," Applied Soft Computing, vol. 30, pp. 595-603, 2015.

[10] J. Menéndez, J. Loredo, M. Galdo, and J. M. Fernández-Oro, "Energy storage in underground coal mines in nw Spain: assessment of an underground lower water reservoir and preliminary energy balance," Renewable Energy, vol. 134, pp. 1381-1391, 2019.

[11] Y. A. Chirkunov and Y. L. Skolubovich, "Nonlinear threedimensional diffusion models of porous medium in the presence of non-stationary source or absorption and some exact solutions," International Journal of Non-linear Mechanics, vol. 106, pp. 29-37, 2018.

[12] X.-D. Song, H.-Y. Wu, F. Liu et al., "Three-dimensional mapping of organic carbon using piecewise depth functions in the red soil critical zone observatory," Soil Science Society of America Journal, vol. 83, no. 3, pp. 687-696, 2019.

[13] A. Jahanbakhshzadeh, M. Aubertin, and L. Li, "Three-dimensional stress state in inclined backfilled stopes obtained from numerical simulations and new closed-form solution," Canadian Geotechnical Journal, 2018.

[14] A. Kapahi and H. S. Udaykumar, "Three-dimensional simulations of dynamics of void collapse in energetic materials," Shock Waves, vol. 25, no. 2, pp. 177-187, 2015.

[15] G. Prerna and S. David, "Three-dimensional multicomponent vesicles: dynamics \& influence of material properties," Soft Matter, vol. 14, no. 1, pp. 1-7, 2018. 